\title{
Trichorhinophalangeal syndrome type I: symptoms and signs, radiology and genetics
}

\author{
SVEN NOLTORP, ${ }^{1}$ ULF KRISTOFFERSSON ${ }^{4}$ NILS MANDAHL,${ }^{4}$ \\ LEIF STIGSSON, ${ }^{2}$ BJÖRN SVENSSON, ${ }^{1}$ AND CARL-OLOF WERNER
}

From the ${ }^{1}$ Division of Rheumatology, Department of Medicine, the Departments of ${ }^{2}$ Radiology and ${ }^{3}$ Orthopaedic Surgery, Nya Lasarettet, Helsingborg, Sweden; and the ${ }^{4}$ Department of Clinical Genetics, Lasarettet $i$ Lund, Sweden

SUMmARY The present study shows the occurrence of the trichorhinophalangeal syndrome type $I$ in a Swedish family. Five members were affected and they were examined clinically and radiologically, and four of them were also cytogenetically examined. Three of them had dysplasia of the hip joints reminiscent of the Legg-Calvé-Perthes disease. Functional hand problems were common. High resolution $G$ banding displayed normal chromosome complements. The inheritance was autosomal dominant. The data presented stress the importance of identifying the syndrome early in life so as to prevent the development of impaired hand and hip function.

Key words: dysplasia of the hip, cone-shaped epiphyses, dominant inheritance.

In $1956 \mathrm{Klingmüller}^{1}$ presented the first description of a triad of symptoms that 10 years later was named the trichorhinophalangeal syndrome (TRPS) by Giedion. The main characteristics of TRPS are sparse, slowly growing scalp hair, a pear-shaped broad nose, and short, deformed fingers with cone-shaped epiphyses of some of the middle phalanges of the hands. ${ }^{2}$ Additional features may occur, e.g., short stature, Perthes-like changes in the hips, short great toes, a long philtrum, a thin upper lip, and medially thick, laterally thin, or absent eyebrows-'the Herthoge sign'. ${ }^{34}$ There are two different types of TRPS. TRPS type I usually shows an autosomal dominant inheritance, though an autosomal recessive inheritance has also been described. ${ }^{3}$ TRPS type II occurs sporadically and is associated with mental retardation and multiple exostoses. ${ }^{5}$ In addition, chromosomal abnormalities have been described in several cases in TRPS type II. $^{6}$ We wish to report a Swedish family with this syndrome, since it obviously has rheumatological significance. Our observations of symptoms and signs and radiological findings are reported as well as some aspects on the genetics of this syndrome.

Accepted for publication 14 June 1985.

Correspondence to Dr S Noltorp, Division of Rheumatology, Department of Medicine, Nya Lasarettet i Helsingborg, S-251 87 Helsingborg, Sweden.

\section{Patients and methods}

CLINICAL AND RADIOLOGICAL

OBSERVATIONS

Fig. 1 shows the pedigree of the family, which comprised 25 members, including two husbands married into the family. Five members were affected with TRPS I and another two members were probably affected, one of whom was appraised from photographs. The remaining members did not show any signs of TRPS I; three were examined clinically and observations about the others were based on interviews and photographs, except for one member with unknown phenotype, who died 8 days old.

Table 1 summarises in comparison with previous reports from the literature the clinical signs of TRPS I in those five members of the family who were affected.

Thus all five, the proband, her two sons, her mother, and brother (Fig. 1), showed the characteristic appearance consistent with TRPS I, i.e., fine, sparse scalp hair, laterally absent eyebrows, and the typical pear-shaped nose (Fig. 2). The potential rheumatological significance of this syndrome is suggested by the uniform presence of hand deformities and limited mobility of the hip joint. In addition to the signs listed in Table 1 brittle nails, leuconychia, and supernumerary teeth were occasionally found. All five complained of hip pain, and three had problems with the hands. 
Table 2 summarises the radiographic observations in the five affected family members compared with previous reports from the literature. Constant findings were short and proximally cone-shaped epiph- yses of the middle phalanges of the index and littleen. fingers (Fig. 3). The thumb metacarpals were shor in the proband and her brother. Short phalanges and? cone-shaped proximal epiphyses were also found in

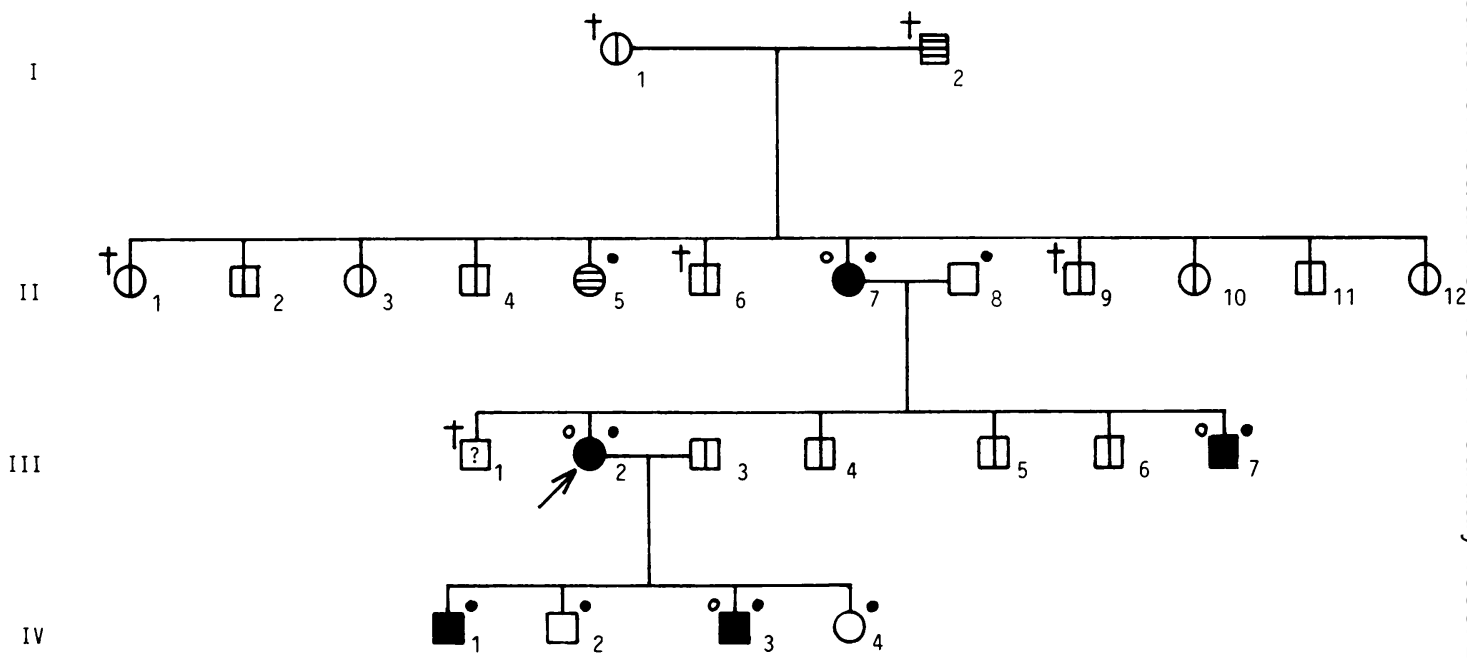

- clinically examined

- cytogenetically examined

$\eta$ proband

+ dead

? unknown phenotype

Fig. 1 Pedigree of the family.

Table 1 Clinical signs of TRPS I compared with previous reports in the literature*

\begin{tabular}{|c|c|c|c|c|c|c|}
\hline & $\begin{array}{l}\text { Common or } \\
\text { mentioned } \\
\text { in the } \\
\text { literature }\end{array}$ & Proband & Mother & Brother & Son 1 & 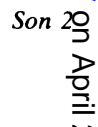 \\
\hline Fine, sparse scalp hair & $\mathrm{C}$ & + & + & + & + & + \\
\hline Light coloured hair & $\mathrm{C}$ & - & - & + & + & + \\
\hline Sparse eyebrows laterally & $\mathrm{C}$ & + & + & + & + & + \\
\hline Bulbous nose & $\mathrm{C}$ & + & + & + & + & $+\omega$ \\
\hline Long philtrum & $\mathrm{C}$ & + & + & + & + & $+\quad \underbrace{\circ}$ \\
\hline Thin upper lip & C & + & + & + & + & + \\
\hline Dental malocclusion & $\mathrm{C}$ & + & + & - & - & + \\
\hline Short stature & $\mathrm{C}$ & + & + & + & + & + \\
\hline Hypermobile joints & $\mathbf{M}$ & + & + & + & + & - \\
\hline Short middle phalanges of fingers II and V & $\mathrm{C}$ & + & + & + & + & + \\
\hline $\begin{array}{l}\text { Lateral instability in proximal interphalangeal } \\
\text { joints of the hand }\end{array}$ & & & & & & \\
\hline & $\begin{array}{l}\mathrm{C} \\
\mathrm{C}\end{array}$ & $\begin{array}{l}+ \\
+\end{array}$ & + & + & + & + \\
\hline $\begin{array}{l}\text { Reduced range of movement in the nip joint } \\
\text { Small feet and short great toes }\end{array}$ & $\mathrm{C}$ & $\begin{array}{l}+ \\
+\end{array}$ & $\begin{array}{l}+ \\
+\end{array}$ & $\begin{array}{l}+ \\
+\end{array}$ & $\begin{array}{l}+ \\
+\end{array}$ & $\begin{array}{l}+ \\
-\end{array}$ \\
\hline
\end{tabular}


Trichorhinophalangeal syndrome type I
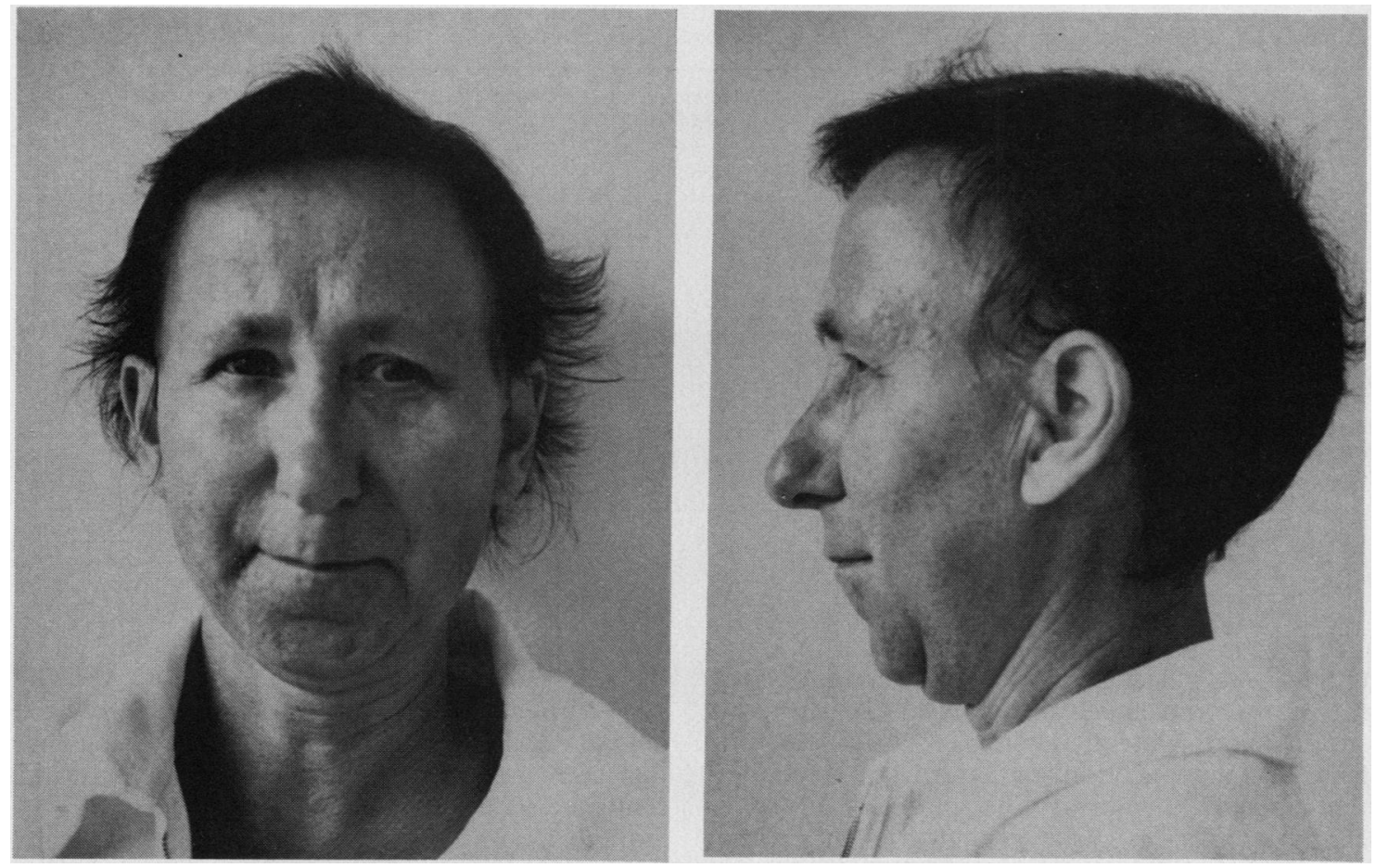

Fig. 2 The proband. Note the fine, sparse scalp hair, sparse eyebrows laterally, and a bulbous nose characteristic of the trichorhinophalangeal syndrome type I (TRPS type I).

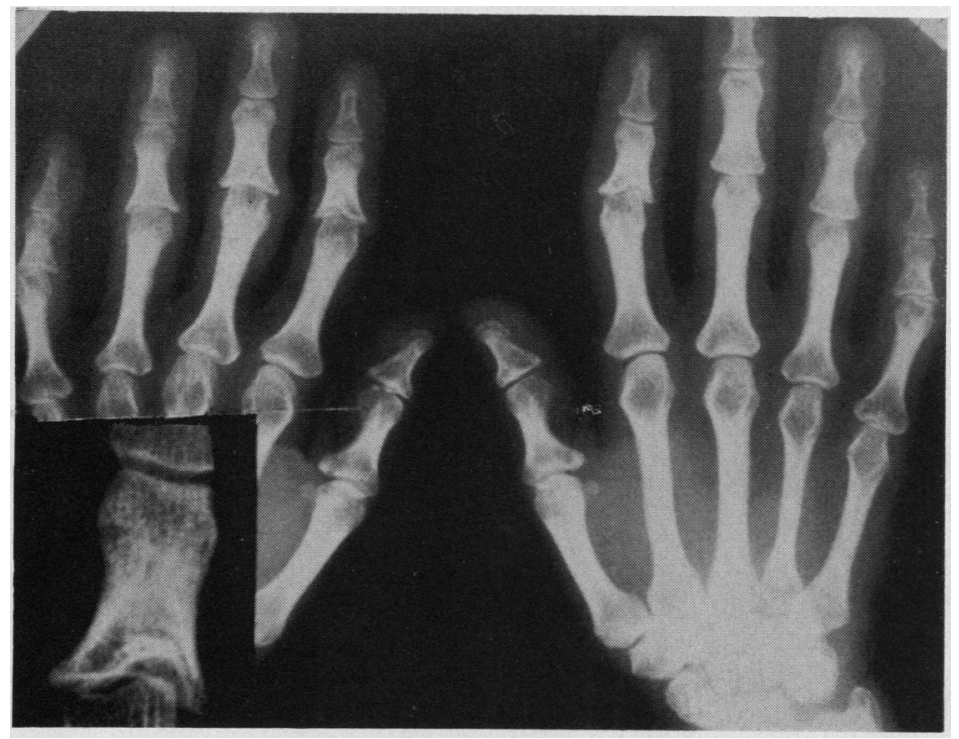

Fig. 3 The proband's hands. Short middle phalanges with cone-shaped proximal epiphyses of the index and little fingers bilaterally, as well as of the middle and ring fingers of the left hand. 
Table 2 Radiographic signs of TRPS $I$ in the hands and pelvis compared with previous reports in the literature*

\begin{tabular}{|c|c|c|c|c|c|c|}
\hline & $\begin{array}{l}\text { Common or } \\
\text { mentioned } \\
\text { in the } \\
\text { literature }\end{array}$ & Proband & Mother & Brother & Son 1 & Son $2 \frac{5}{7}$ \\
\hline $\begin{array}{l}\text { Cone-shaped epiphyses of the middle phalanges of } \\
\text { digits II and V }\end{array}$ & $\mathrm{C}$ & + & + & + & + & + \\
\hline $\begin{array}{l}\text { Hypoplasia of the middle phalanges of } \\
\text { digits II and V }\end{array}$ & $\mathrm{C}$ & + & + & + & + & + \\
\hline Hypoplasia of the thumb & $\mathrm{C}$ & + & + & + & - & + \\
\hline Short or slender metacarpal bones & $\mathrm{C}$ & + & + & + & + & - \\
\hline Dysplasia of the hip joint & $\mathrm{C}$ & - & + & - & + & + \\
\hline Broad femoral neck & $\mathrm{C}$ & - & + & - & + & + \\
\hline Coxa magna & $\mathrm{C}$ & - & + & - & + & + \\
\hline Coxa vara & $\mathrm{C}$ & + & + & - & + & + \\
\hline Deformation of the symphysis & $\mathbf{M}$ & + & + & + & - & - \\
\hline
\end{tabular}

*+present; - absent: $\mathrm{C}=$ common: $\mathrm{M}=$ mentioned.

the proximal phalanges of the big toe in son 1 and in the proximal phalanges of the three medial toes in son 2. Uni- or bilateral dysplasia of the hip joint with a broad femoral neck and coxa magna were found in three family members. The mother had some cartilage reduction in her hip joints combined with a unilateral acetabular protrusion. Slight deformation of the symphysis was observed in the mother and the brother, whereas the proband herself had a pronounced symphyseal deformation. Other radiographic findings, not shown in the table, were slight spinal scoliosis in the mother and the two sons, prominent ulnar epicondyles in son 1 , and sacroiliac sclerosis in the proband. Generally slender ribs were observed in the proband. Similar findings were made in ribs III and VI of son 2.

\section{PATIENTS}

The proband (Fig. 2) is a 44-year-old woman. Except for frequent infections during her childhood she was healthy up to her early forties. At 41 years气 of age she got pain in her knees and left hip. She also felt pain in the fingers of both hands. On examina- $\stackrel{\infty}{\infty}$ tion there were signs of arthritis in her left knee? combined with an extension deficit. The range of movement in the left hip was limited. Both handss showed decreased range of finger motion and ulnar lateral instability in the proximal interphalangeal

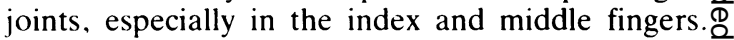
Fig. 3 shows the radiographic pictures of her hands. $\overrightarrow{\vec{*}}$ The grip strength was bilaterally reduced. Because $\frac{3}{3}$ of the joint symptoms she could not work full time as a seamstress. The lack of stability in the proximato interphalangeal joints gave a bad and painful pinch grip. Arthrodesis of the proximal interphalangealōo joint of the right index finger was undertaken to improve the hand function. At the operation, performed in a bloodless field, there was no sign ofo synovitis; neither was there any erosion of the cartilage. On joint resection the bone was found to음

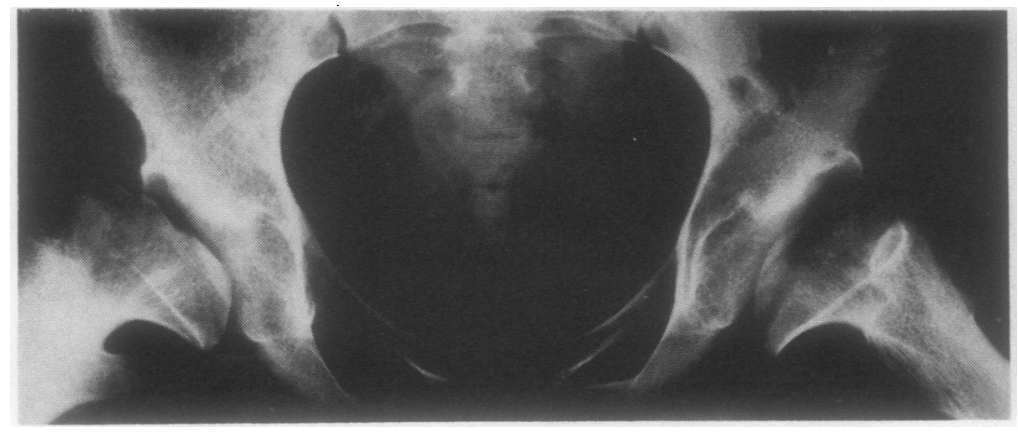

Fig. 4 Dysplastic hips in TRPS I. The femoral neck is short and broadened; the femoral head is deformed and broad and has a smooth central groove. The acetabula are enlarged and dysplastic. 


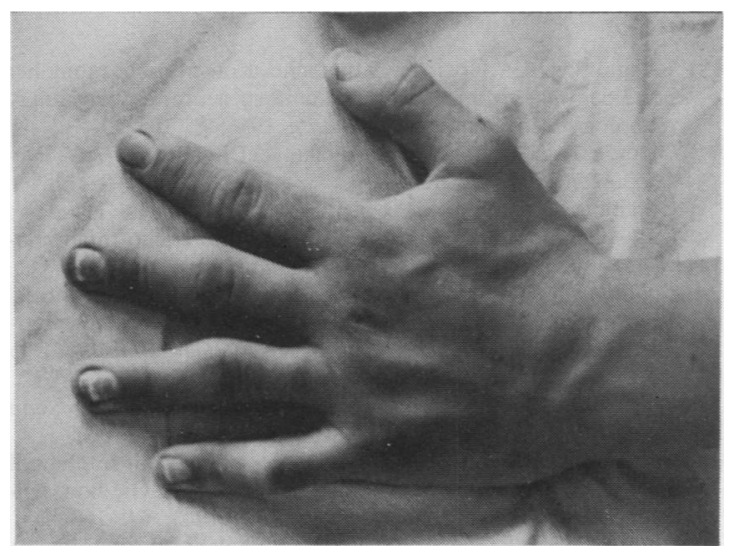

Fig. 5 Finger deviation, hypoplasia of the middle phalanges, and leuconychia in TRPS I.

be surprisingly hard. The arthrodesis healed without complications.

Haemoglobin, erythrocyte sedimentation rate, tests for antinuclear antibody and rheumatoid factor, and urinalysis were performed in all five affected members of the family, with normal results. In addition, the following tests were made in the proband and found to be within normal limits: plasma electrophoresis, $\mathrm{C}$-reactive protein, the complement components $\mathrm{C} 3$ and $\mathrm{C} 4$, liver profile, thyroid hormones, blood lipids, serum creatinine, blood glucose, serum calcium and phosphorus, serum uric acid. She lacked HLA-B27 in her tissue antigen type.

The proband's mother, as she remembers, had always suffered from pain in her hands, felt generally weak and unable to perform heavier work. She had a right-sided hip pain in her childhood. At 56 years of age she had a left-sided acetabular fracture. Radiographic examination on that occasion showed severe bilateral coxarthrosis. Five years later she had an arthroplasty of the right hip.

The proband's brother is healthy except for occasional pains in his left hip.

One of the proband's two sons affected with TRPS I, now 22 years old, started to have pains in his hips at 15 . Our examination showed a bilaterally reduced range of hip movement, and radiography demonstrated bilateral dysplasia of the hip joints (Fig. 4). His hands showed the characteristic findings of TRPS I, but he has had no pain or other hand problems so far.

The other son, now 16 years old, started to have pain in his left hip when he was 10 . On examination at that time a dysplasia of his left hip joint was diagnosed. In addition, abnormalities of his hands had developed, such as inability to clench his left hand (he is left handed) and moderate flexion contractures of the index fingers (Fig. 5).

One of the proband's aunts on her mother's side may also have TRPS I. She is small, has the Herthoge sign, a bulbous nose, a poorly demarcated philtrum, and a thin upper lip. Her hands do not show the typical changes, and she has no pains in her hips.

The proband's grandfather on her mother's side might also have had the syndrome. Examination of photographs showed small fingers and the Herthoge sign.

\section{GENETI CS}

Chromosome analyses were performed on cultured peripheral blood lymphocytes from the proband, her mother, her affected brother, and one of her affected sons. High resolution $\mathrm{G}$ banding (actinomycin $D$ and trypsin $G$ banding) was applied. The analyses of all four subjects displayed normal chromosome complements. Neither chromosome 8 , to which special attention was paid to the $8 \mathrm{q} 2$ region, nor chromosomes 9 or 11 were found to be structurally abnormal. The inheritance in our family is autosomal dominant (Fig. 1).

\section{Discussion}

The symptoms and signs of TRPS I observed in our family are in agreement with previous reports. ${ }^{37}$ Although TRPS type II is a diagnostic alternative, this possibility is ruled out by the absence of micrencephaly, mental retardation, and multiple cartilaginous exostoses. In addition, inheritance is not reported in TRPS II, whereas our family showed an autosomal dominant inheritance. In several cases the TRPS II has been found associated with a deletion in the distal region of chromosome 8 , the break point being at variance in the bands of q22q24 in the different reported cases. ${ }^{6} 8$ As there is an overlapping in the clinical picture of the two syndromes, the possibility that TRPS I also could be due to a deletion in the same region has been discussed. However, the cytogenetic data in the present study and the results of a case reported by Gaardsted et al. ${ }^{9}$ do not show any such abnormality in any of the four cases analysed. These findings, however, do not exclude a submicroscopical deletion in band $8 \mathrm{q} 23$ region as the cause of TRPS I. A de novo 9:11 translocation has been described in a sporadic case of TRPS $\mathrm{I}^{10}$ The regions involved in translocation displayed a normal feature in our family.

Three of our cases had dysplasia of the hip 
reminiscent of the Legg-Calvé-Perthes disease. This disorder is believed to be due to an aseptic bone necrosis. ${ }^{11}$ However, in a report of 16 patients with TRPS I Felman suggested that the hip dysplasia in TRPS I might be due to a delayed mineralisation, leading to deformity when putting weight on a still largely cartilaginous epiphysis. ${ }^{12}$ Whatever the cause of the dysplasia it might be of importance to identify the condition in an early stage to bring about maximal prevention of deformity. Proper guidance towards suitable occupation is of course of importance in this respect. Should the deformity progress, secondary coxarthrosis might ensue, necessitating arthroplasty of the hip.

Functional hand problems in patients with TRPS I seem rare as reported in the literature. ${ }^{3}$ However, in our family the proband, one of her sons, and her mother had such problems, which interfered with the activities of daily life. Thus the lack of a stable pinch grip as it occurred in the proband had to be corrected with an arthrodesis of the proximal interphalangeal joint of the index finger. A similar procedure is planned for the other hand.

In conclusion, the present study shows the occurrence of the TRPS type I. The data presented stress the importance of identifying the syndrome early in life so as to prevent the development of impaired hand and hip function.

\section{References}

1 Klingmüller G. Über eigentümliche Konstitutionsanomalien $\overrightarrow{\overline{\vec{n}}}$ bei 2 Schwestern und ihre Beziehung zu neuren entwicklungs:pathologischen Befunden. Hautarzt 1956; 7: 105-13.

2 Giedion A. Das tricho-rhino-phalangeal Syndrom. Helv Pae $\overline{\bar{D}}$ diatr Acta 1966; 21: 475-82.

3 Giedion A, Burdea M, Fruchter Z, Meloni T, Trosc V. $\overparen{\Phi}$ Autosomal-dominant transmission of the tricho-rhino-phalangeal syndrome. Helv Paediatr Acta 1973; 28: 249-59.

4 Goodman R, Trilling R, Hertz M, Horoszowski H, Merlob P, $\rightarrow$ Reisner S. New clinical observations in the tricho-rhinophalangeal syndrome. J Craniofac Genet Dev Biol 1981; 1: 15-29.

5 Hall B D, Langer L O, Giedion A, et al. Langer-Giedion? syndrome. Birth Defects 1974; 10: 147-64.

6 Bühler E M, Bühler U K, Christen R. Terminal or interstitial deletion in chromosome 8 long arm in Langer-Giedion syn. drome (TRP II syndrome)? Hum Genet 1983; 64: 163-6.

7 Peltola J, Kuokkanen K. Tricho-rhino-phalangeal syndrome in $\omega$ five successive generations: report on a family in Finland. Acta $\mathrm{O}$
Derm Venereol (Stockh) 1978; 58: 65-8.

8 Fryns J P, Heremans G, Marien J, Van den Berghe H. Langer- $-\overrightarrow{-}$ Giedion syndrome and deletion of the long arm of chromosome 8. Confirmation of the critical segment to 8q23. Hum Genes 1983; 64: 194-5.

9 Gaardsted C, Hjöllund Madsen E, Friedrich U. A Danish kindred with tricho-rhino-phalangeal syndrome type I. Eur $J$ Pediatr 1982; 139: 84-7.

10 Booth C W, Maurer W F. De novo 9:11 translocation in a sporadic case of trichorhinophalangeal (I) syndrome [Abstract] Pediatr Res 1981; 15: 559.

11 Ponseti I, Maynard J, Weinstein S, Ippolito E, Pous J. Legg Calvé-Perthes disease. J Bone Joint Surg 1983; 65A: 797-807

12 Felman A, Frias J. The trichorhinophalangeal syndrome: studj of 16 patients in one family. Am J Roentgenol 1977; 129: 631-8. 